\title{
A Spatial Analysis of Precarious Forms of Employment in France
}

\author{
by
}

\section{Marc Jacquemond}

A Thesis Submitted in Partial Fulfillment of the Requirements for the Degree of B.A. in Geography - Urban Systems

\author{
Department of Geography \\ McGill University \\ Montréal (Québec) Canada
}

April 2012

(C) 2012 Marc Jacquemond 


\section{ACKNOWLEDGEMENTS}

First and foremost, I offer my sincerest gratitude to Professor Sébastien Breau as without his support, encouragement, knowledge and patience this thesis would not have been anywhere near the product it is now. His supervision, passion and teaching have undeniably been one of the most pleasant academic experiences I have had to date, and will remain a highlight of my time at McGill. Finally, I would like to thank him again for the help and support that he has given me well beyond my thesis.

I also would like to gratefully thank Professor Mario Polèse for being my reader, and prior to that for offering me guidance and stimulating my curiosity with regards to the field of economic geography and empirical research. The patience and time he has given me at the onset of the project were very appreciated.

Finally, I would like to thank my friends and the geography department at McGill for creating an academically challenging and inspiring environment that has pushed me to become a better and more driven student. 


\section{TABLE OF CONTENTS}

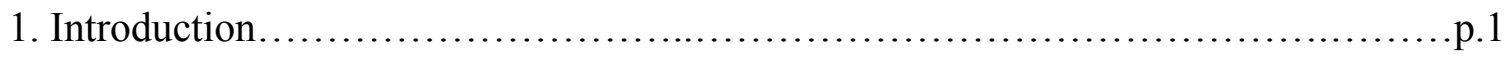

2. Literature Review....................................................... 4

3. Data and Methodology

3.1. Data. p. 12

3.2. Methodology

3.2.1. Spatial Statistics Methods..........................................p. 14

3.2.2. Exploring Urban \& Rural Locales.........................................p.16

3.2.3. Bivariate Moran's I.................................................p. 17

4. Results and Analysis

4.1. Exploratory Results

4.1.1. France as a Whole.............................................. 18

4.1.2. At the Regional Level............................................ 18

4.1.3. An Urban/ Rural divide.........................................p.19

4.2. Assessing the Spatial Patterns of Precarious Employment

4.2.1. Aggregate Indicators of Spatial Autocorrelation........................p. 21

4.2.2. Local Indicators of Spatial Autocorrelation............................p. 22

4.2.3. A Typology of Spatial Patterns....................................p. 23

4.2.4. Another Urban/Rural Divide in Clustering Typologies?.................p. 24

4.3. Discussion..................................................... 25

4.4. Exploring the Localization of Precarious Employment.......................p.27

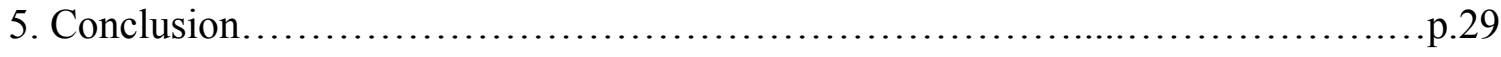

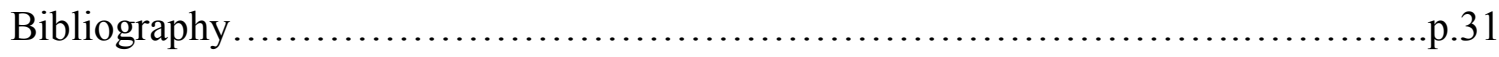

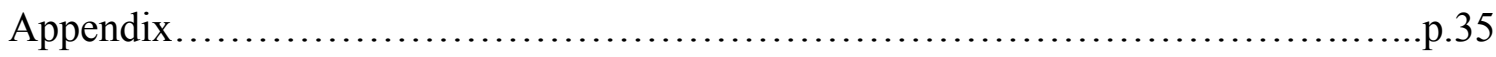




\section{LIST OF FIGURES}

1.Hierarchy of French administrative units in descending order of aggregation in 2012 (including French overseas departments).... p. 35

2. Summary statistics of precarious employment in France.......................................p. 35

3. Regional levels of precarious forms of employment...........................................p. 36

4. Pearson's correlation coefficients among employment types................................p. 37

5. Mean and standard deviation of the four precarious employment variables for urban

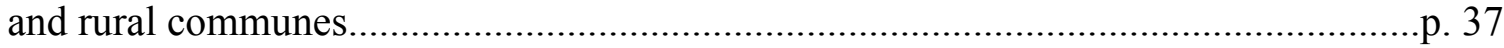

6. Global Moran's I values and pseudo p-values for each employment form...............p. 37

7. LISA map of part-time work in France................................................................p. 38

8. LISA map of contracts of limited duration in France..........................................p. 39

9. LISA map of Interim work in France........................................................... 40

10. LISA map of subsidized employment in France..............................................p. 41

11. LISA outputs for France as a whole...................................................................p. 42

12. LISA outputs for urban and rural communes...............................................p. 42

13. Bivariate Global Moran's I results, by population characteristic.........................p. 43 


\begin{abstract}
This research focuses on the topic of precarious (or atypical) forms of employment in France in 2008. This research addresses the geographic gap in the related literature through various exploratory spatial statistics based on data from the INSEE (Institut National de la Statistique et des Études Économiques). The results show that there is indeed a discernible spatial pattern of hot spots and cold spots in the distribution of precarious forms of employment across the French territory. I notably find that urban areas displayed statistically lower levels of precarious employment for part-time work and contracts of limited duration than rural areas, whereas the opposite situation was found for both interim and subsidized employment. socio-economic variables were determined to be more strongly associated to precarious employment than industrial variables.
\end{abstract}




\section{Chapter 1: Introduction}

The spring of 2006 saw one of the largest demonstrations in recent French history, a demonstration in which the retired, youth and employees took to the streets to denounce high unemployment rates and precarity. Though the estimates of the police and unions differed, it was estimated that between 892000 and 2680000 individuals (Le Monde, 2006) demonstrated all across France on march $28^{\text {th }} 2006$ to denounce a new government

policy seeking to introduce further legal flexibility in the job market, notably by enabling employers to fire their workers without motivating their decision. Large urban areas were the epicentres of this large demonstration, according to unions, 700000 individuals marched in Paris while 250000 did in Marseille. In this context of public discontent, social justice groups such as the French NGO ATTAC (Association pour la Taxation des Transactions Financières et pour l'Action Citoyenne) have raised awareness on such recent developments in the French labour market and have gone on to denounce it as a symptom of neoliberal governmental policies aimed at deregulating labour markets (ATTAC, 2006). Even though this new policy has been poorly received insofar as it challenged previously acquired social benefits, the French labour market has de facto been undergoing some overwhelming changes.

The French labour market has been undergoing a radical change in the recent past. A new range of uncertainties and challenges to what had come to be referred to as the "norm of full employment" emerged. It is with a certain nostalgia that the French public recalls the expression «The Glorious Thirty», an expression that references back to a time spanning from the 1950s to the end of the 1970s, that had been characterized by fullemployment and continued economic growth (Givord, P., 2005). The departure from this time is often traced back to the early 1980s where a major event occurred in the national French labour market landscape, that of "la précarité" (precarity in english). (Givord, P. 2005). Defining precarity often causes issues, as the French statistical agency - the INSEE (Institut National de la Statistique et des Études Économiques) - mentioned, there is no one way of defining precarity, and studying the phenomenon raises methodological and theoretical issues (INSEE, 2005) depending on how one understands precarity. 
First, precarity may be understood as precarity at work, which relates to the relationship of the employee to his or her job, i.e. the appreciation of work conditions or the feeling of job security (Rolfsen, L. et al, 2001). This definition is particularly relevant from a psychological standpoint and depends on individual experiences.

Second, the concept of precarity can be understood as precarious forms of employment. In that sense, it refers to the contractual relationship of employment that diverges from "standard" categories, where "standard" typically consists of a full-time and stable employment situation (Cottrell, M. et al, 2002). Although "precarious" is the most widespread appellation for this form of employment in France, appellations may differ from country to country, ranging from names such as standard, contingent or atypical forms of employment (McDowell, L. et al., 2009).

In the French context, precarious forms of employment can be identified as jobs with contracts of limited duration (the so-called "contrat à durée indéterminée, CDD), subsidized employment, part-time work, and interim work (temporary contracts) (Ribardière, A., 2005) - see also Chapter 2 for more details on each form of employment). What all these different forms of precarious forms of employment share in common is that contrarily to the CDI (contract of unlimited duration) which is the standard form of employment, the four aforementioned job contracts typically have an end date and/or involve shorter hours of work (Cottrell, M. et al, 2002) with less job security (Paugam, 2000). They are also often associated to a fluctuating and generally lower revenues (Cottrell, M. et al, 2002).

As previously observed, the concept of precarity generally holds a negative connotation. Indeed, precarity is often linked to poverty and other forms of precarity, such as housing insecurity and other psychological and health issues that are often grouped under the more holistic situation of "social precarity" (Hélardot, V., 2004). The substantial increase in such forms of employment is therefore widely received from a critical point of view. All in all, the share of precarious forms of employment in total employment practically doubled between 1992 and 2000, even when the total increase in employment is controlled for (Perez, C. et al, 2005). It is also an issue that affects the French population differently, particularly women (Maruani, M., 2004) and the youth (Givord, P., 2005) are often defined as populations at risk in the literature on the topic. 
Based on the realization that precarity is a growing phenomenon with social, political and economic underpinnings, the research carried out in this thesis seeks to contribute to the growing body of knowledge on the matter while allowing for a new understanding of the topic. Specifically, this research will attempt to provide a spatial analysis of precarious forms of employment across France. Indeed, as will be discussed in the literature review (Chapter 2), much of the literature has focused on aggregate indicators of precarity or indirectly attempted to study precarity from a local standpoint, and remains silent as to the spatial arrangement of precarious employment across the French territory. To do so, the disaggregate spatial data provided by the 2008 Census of the INSEE will be processed and computed using different exploratory spatial analytic methods (Chapter 3 and 4). Using these different methods, this research will interrogate the following questions: does precarious employment exhibit a spatial pattern? If it does, what kind of pattern is most dominant across the French territory? Finally, what may explain the geographic distribution of precarious employment in France? Such questions, while interesting in and of themselves are also particularly relevant from a social justice and policy standpoint. An in-depth description of the differentiated geography of precarious forms of employment provides a starting point for local policies targeted at alleviating some of the clusters of precarity which may be observed across France. Moreover, assessing the determinants of precarity from a geographic standpoint introduces greater refinement for a policy approach attempting to target the roots of precarity in given areas.

The remainder of this thesis is organized as follows. In Chapter 2 discusses the relevant literature on the topic with a special focus on France and geographic studies of precarity and labour phenomena. Chapter 3 presents a review of the data from the INSEE and the exploratory spatial statistics methods used in this research, notably the local and global moran's I. Chapter 4 provides an overview of the results and a typology of the spatial patterns found. Finally, Chapter 5 concludes the research. 


\section{Chapter 2: Literature Review}

Though the use of the term "precarious" forms of employment is still relatively new in English-speaking academic circles, it has a longer history in some European countries. In French academia, Bourdieu initially coined the term to the employment patterns of casual workers in Algeria and concluded that they were undergoing conditions of precarity in the 1960s (Waite, 2009). The concept was not introduced to the study of the French employment context until the 1980s. As noted earlier, the French labour market did not feature a substantial number of work situations of an instable or nonnormal type (Tuchszirer, C. 2005). While the phenomenon has been studied in various contexts it is necessary to mention that unlike other socially relevant themes it cannot be thought of as a homogenous category so that understandings of precarity may vary depending on the place of study (Tuchszirer, 2005). Before coming back to the more specific French context it is important to highlight how precarious forms of employment are commonly understood along with the processes that are associated to the phenomenon.

\subsection{Academic Context of the Notion}

Precarity, in general, has been casted as a characteristic of neo-liberal and postindustrial economies (Dörre, 2006), and of society at large (Offredi, 1988). In particular, precarity is often associated with the characteristic flexibility of post fordist economies. This is important insofar as the global geography of the post fordist economy is differentiated. Obenhauser (1990) notably explained that post fordist economies generated a pressure for flexibility on both highly and lower skilled work, and that the spatial division of labour was increasing. This entails that precarity is tied to greater processes that follow a discernible geographic pattern.

On a similar note, according to Gialis and Karnavou, (2009), the contemporary context of globalization and free circulation of capital, labour, products and services creates instabilities and uncertainties. The geography behind those common processes was addressed by Peck, J. According to him, localities are under sharp competition to attract free moving capitals and thereby adopt specific policies and strategies to attain this goal (Peck et al., 2002). In other words, the contemporary economy would be 
characterized by both advanced internationalization - i.e. of capital flows - and high localization (Gialis \& Karnavou, 2009) so that these uncertainties - also called "precarity" - are particularly targeting the local level.

Precarity has also been studied in very tangible ways, especially with regards to the social, political, psychological and economic ramifications of the phenomenon. In the specific context of labour, some have argued that the increased flexibility of employment constitutes a condition for improving national economies (Siebert, 1997) others have also seen the process as creating work fragmentation and contributing to a deterioration of the status of employees (Reimer, 2003). Moreover, according to Vassilis Tsianos precarity is at the very center of the crisis of society as it erodes the national social compact of normal employment. Beyond a mere exploitation of the workforce, the exploitation in itself would extend to many aspects of everyday life since it puts the worker in a state of constant questioning about the future and the present (Tsianos et al, 2006).

Robert Castel (2005) provides another interesting political understanding of the phenomena which is tied to the French context. According to him, the modern employment context puts people who suffer from exclusion from labour markets in direct competition to each other which may cause a rise in xenophobia, racism and right-wing party affiliations. Mansel, (2010), on the other hand maintained that the local experience of precarity and poverty may lead to feelings of powerlessness and inability to change one's own situation which often translates into political apathy. Precarity may therefore have far reaching consequences in political terms. Regarding the social aspects of the issue, the origins of precarity in academic literature are also to be linked with that of poverty. What previously seemed like an oxymoron - employment and poverty - became known as the "working poor" phenomenon. By the 1980s the word was also used in social movements and increasingly so in the 1990s, in a similar fashion to precarity (Waite, 2009).

\subsection{Defining Precarious Forms of Employment in France}

Before pursuing this survey of the French literature on precarity, it is important to define what are commonly understood as precarious forms of employment in the French context. According to the French Inequality Observatory (2008) and the French Statistical 
Agency (INSEE, 2011), contracts of limited duration, subsidized and Interim work are part of the precarious forms of employment category. These all refer to different employment and legal situations. Contracts of limited duration (abbreviated as CLD) have an end-date in comparison to the predominant contracts of unlimited duration ( $a b b$. CDI in French). Subsidized work involves incentive strategies for employers that are provided by different levels of government and are designed to help underprivileged jobseeking individuals. Interim work, on the other hand, describes a rather different situation as it involves a triangular relation between employees, employers and temporary staffing agencies. For interim work, temporary staffing agencies act as intermediaries that provide contract workers for companies (Johns \& Ward, 2009). Interim work is considered as a precarious form employment since the end-date for the work contract is often not fixed. Moreover, interim and CLD contracts are often the first ones not to be renewed in hard economic circumstances (French Inequality Observatory, 2008). The final category is often much debated and was purposely left out by the French Statistical Agency - the part-time work typology. Part-time work (abbreviated as PT) encompasses different realities as well and can be typified as either part-time by choice or part-time for lack of options. It was estimated by the French Observatory on Inequalities (2010) that about a quarter of individuals working part-time would have preferred to work more, so that they fit into the part-time for lack of options category. The institution warns that these figures may be deflated as respondents may state that they do not wish to work more because of hard work conditions and/or low salaries acting as a disincentive.

\subsection{Aggregate Studies of Precarious Forms of Employment in the French Academic}

\section{Literature:}

There is now a growing interest on precarious forms of employment in the academic and policy literature as evidenced by the numerous articles and official reports done on the topic. Yet, as Mathieu (1997) argued, the research carried out on social matters in France has often overlooked spatial and geographic distributions as topics of interest in the past (Mathieu, 1997).

The academic literature tends to focus on aggregate trends and identifying populations that are particularly at risk of precarious employment. Particularly, precarity is thought to target individuals who are in a state of dependency. Women and the youth 
have consistently been identified as "populations at risk" in that the former depend on their husbands, and the latter depend on their family. In terms of figures, in 2006, one in three youth occupied an atypical form of employment, almost one third of women occupied a part time job, whereas only $6 \%$ of males did. Single headed family households have also been associated with precarious forms of employment which puts them under great vulnerability (Concialdi, 2006).

It has been observed that, overall, since the beginning of the 1980s, part time and temporary types of work have substantially increased, i.e. the total number of interim workers has increased fivefold between 1993 and 2001, while internships, interim and subsidized employment increased by 300\% between 1982 and 2002. During that same period, the working population in France only increased by 9\% (Givord, 2005). In total, precarious forms of employment increased by 2.5 million jobs between 1983 and 2005 . This is a particularly significant increase in that it absorbed $60 \%$ of the total growth of salaried employment during that same period (Concialdi, 2006).

As was said earlier, this increase is worrisome for many reasons. Precarious forms of employment have often been associated to poverty, reduced revenue and health concerns (Hélardot, 2005). Another concern which is often raised is that although precarity may be a temporary situation for some, while for others it represents a long lasting situation which further entrenches the associated repercussions that were previously addressed. In that sense, individuals in such a situation may reach a vicious circle in which precarity represents a dead-end. As Perez \& Thomas argued (2005), people tend to move on from one form of precarious employment to another without gaining access to a stable employment situation. In this time continuum approach, continuing education is often heralded as a solution to this ongoing repetition. However, a stable employment relation is often a precondition for access to continuing education which may explain partly why precarity constitutes a dead-end. Indeed, according to Human Capital Theory, employers prove reluctant to invest in continued education for their employees if they consider that the employee will stay for a small duration of time. Consequently, they would be more likely to invest in skills that are less transferable and that imply a longer employment relation over time (Perez and Thomas, 2005).

As previously observed, precarity is considered to be a differentiated phenomena in that it affects different populations in different ways. Interestingly, the geographic 
differentiation of the problem has received little attention in terms of its geographic distribution. Patacchini and Zenou (2007) made a similar observation, though for the topic of unemployment, by arguing that little research has been done on the spatial interdependence between regional labour markets and unemployment. Since no literature was found to be directly addressing the issue of precarious employment in spatial terms, a discussion of a selection of the most relevant work, in terms of methods and focus is to be presented in the following section.

\subsection{Localized Accounts of Precarity in French Academic Literature}

The work of Ribardière (2005), notably, has substantial value for the purposes of this research. According to her, the local context may affect the experience of precarity and sometimes contribute to determining the level of precarity and social exclusion at large. It is important to highlight that her understanding of precarity is somewhat different to that of this research. She considers social precarity as a whole that is, including housing and occupational variables in her analysis so that precarious forms of employment constitutes a variable among others, which is different to the focus of the research to be conducted here. Her argument is particularly critical as she does not follow an environmental determinism approach to the phenomenon whereby the social context surrounding an individual leads to an expected reproduction in social behaviour; instead she understands the local context as acting either as a negative or positive resource. The spatial approach of precarity that she provides can be summed up as follows: whereas the spatial clustering of precarity may play a negative role in worsening exclusion by creating an economically and socially depressed milieu, a more mixed environment may also constitute an opportunity for the more disadvantaged to benefit from sharing educational and cultural facilities. Additionally, she mentions that homogeneity at the local level may also create a sense of solidarity and promote social networks as a safety net against precarity. Mansel and Heitmeyer (2010) also contends that social similarity in a region may promote solidarity and reduce feelings of deprivation as well as possibilities of conflict associated to dissimilar social contexts.

Still, the focus of her research is different to that of this research in another way. Ribardière (2005) solely focuses on the Parisian agglomeration and on social precarity which encompasses both precarity at work and in work. The research to be conducted 
here will focus on precarity in work only, that is, the focus of this study will be that of precarious employment forms rather than precarity as experienced by individuals in the workplace. That being said, she selected the same contract typologies as those to be discussed here, namely, contracts of limited duration (CLD), part-time work (PT), subsidized employment and interim and considers them as central to the notion of social precarity - like Paugam (2000).

She argues that different typologies of social precarity can be observed. The different localized profiles of precarity that she finds stem from the correlation between precarity and "populations at risk" such as: the local concentration of social housing, unemployment, single headed families and large households, as well as non-EU immigrants. Paris stricto sensu stands out in her research considering that it concentrates less social housing, less youth and large households, though the level of non-EU immigrant and single headed families is seen as comparable to other areas of substantial precarity. She notably explained that the reason behind this "precarity in the core" was due to the centrifugal force that large urban settings exert over job-seekers. Overall, she also finds higher levels of precarity in the denser - more urban areas than in the areas of lesser density.

Finally, she classifies the spatial organization of precarity as fitting into three models: "the divided urban space model" where pockets of precarity may be in direct contact with more well-off areas; "the socio-spatial mosaic model" which is characterized by a very contrasted and heterogeneous social profile; and "the massive and diffused precarity model" whereby the entire territory is marked by high precarity levels. The in-depth and localized approach to precarity as well as the overall systematization of her results across the Parisian agglomeration constitute a definite strength in her approach. However, since the research that is proposed here attempts to cover the entire French territory, a "local profile" approach to precarious forms of employment would represent an insurmountable task. It is therefore important to turn to research carried out on the localization of labour forms with the use of more systematic statistical tools.

Having said that, Elisabeth Tovar's (2010) recent research on social and employment segregation in the Parisian agglomeration makes use of spatial statistics tool, though here again at the Parisian metropolitan level. The focus of her research is similar 
to that of Ribardière's, though possibly larger in scope in that it provides a spatial account of the distribution of poverty at large rather than focusing on precarity in the Parisian agglomeration area. Her research pays special attention to the spatial association of her poverty index, a range of socio-economic indicators and lastly, precarious forms of employment which are directly relevant to the purposes of this study. She found in particular that the spatial distribution of poverty in the Parisian region is linked to that of lower and higher income socio-economic profiles. Furthermore, she also points out that some of the most precarious forms of employment - e.g. subsidized employment follow a similar spatial distribution to that of poverty. However, in looking at the details of the spatial distribution of precarious forms of employment she observes that each of those forms of employment follow a different organization and pattern. Interestingly, she observes that those patterns do not necessarily overlay with that of poverty. Even though the core focus of her research is that of poverty and only indirectly tackles precarious employment, her work constitutes one of the only attempts at studying precarious forms of employment using a spatial statistics methodology. Still, her research and that of Ribardière (2005) only focus on the Parisian agglomeration rather than on the French territory as a whole. Therefore, it will be important to discuss research dealing with spatial and economic phenomena at greater scales, particularly with regards to labour issues.

\subsection{Spatial Analyses of Unemployment}

At a more aggregate geographical scale, Patacchini and Zenou (2007) have argued that little research in economy directly addresses regional labour markets and their interdependencies. As Zenou contends: "labour economists and macroeconomists traditionally do not incorporate space into their studies" (2011, p.387). Nevertheless, Cracolici et al. (2009) indicate that more and more research is being done on the topic of the uneven geographic distribution of unemployment rates. Quite evidently, this type of research does not address the question of precarious forms of employment but still makes use of interesting methodologies. Indeed, the research done on unemployment provides an empirical and geographical study of employment variables at a less local scale than the research conducted by Tovar (2010) and Ribardière (2005). 
The general focus of this literature review has been to try and define a model that would provide an understanding of the differentiated unemployment rates across specific countries and regions (Cracolici et al , 2009). Through the use of spatial autocorrelation and econometric tools, Patacchini and Zenouy (2007) suggest that the unemployment rates of neighbouring regions becomes increasingly similar over time. This is an important discovery insofar as it shows that specific labour issues, in that case unemployment, may display a certain level of spatial dependency (Gialis and Karnavou, 2009). This approach has been used for the study of unemployment in Great Britain and in Italy, while similar research of French labour markets were considered to be lacking (Gambier and Vernieres, 1991) even though Aragon et al (2001) have contributed to filling this gap in the French literature in the mean time.

The following research will attempt to directly address precarious forms of employment from a spatial standpoint while using the entire French territory as the unit of study. The following section defines the methods and data used for the purposes of this project. 


\section{Chapter 3: Data and Methodology}

\subsection{Data}

The data used for this research comes from the Employment Characteristics dataset of the 2008 national census which is made publicly available by the French National Institute of Statistics and Economic Studies (INSEE). The data covers the employment forms and conditions of individuals above 15 years of age occupying a job for small administrative units: the communes and arrondissements. As Bernard Simonin argued (2004), the relevant spatial unit of analysis for studying employment policies in France should be smaller than a department and bigger than an agglomeration. The commune and arrondissement level meets the first standard while remaining smaller than an agglomeration. For that reason, the lack of an intermediary administrative unit proves to be a shortcoming for studying labour policies in France. Even so, the communes and arrondissements units are small enough to get a very fine-grained understanding of labour disparities across the territory as the number of spatial units $(n=36588)$ shows (see Fig.1 in Appendix). It is also considered to be the unit of choice for mapping social divisions in France (Ribardière, 2004).

Among the different employment conditions, four were selected based on the literature previously discussed (see Ribardière, 2005; and Chapter 2 for a definition of the terms): subsidized employment (emploi aidé in French), contracts of limited duration (CLD, contrats à durée détérminée in French) which includes short-term contracts and seasonal work, interim employment (interim), and part-time contracts (PT, temps-partiel in French). Since the focus here is on precarious forms of employment and not social precarity in general, the choice was limited to employment contracts.

The aforementioned data was also standardized to account for differentials in the population in age of working (15 years old and over) across spatial units. In doing so, percentages of the labour force working under the previously mentioned types of employment were created.

Understanding what may explain specific concentrations of precarious forms of employment required to select a range of different available variables. The variables under study relate to the demand and supply forces behind labour markets. 
The local demand for labour was assessed using 2008 data from the INSEE website on the characteristics of firms and establishments (INSEE, 2010). This data provides information on the numbers of firms in given economic sectors for each commune and therefore serves as a proxy for the industry composition of a given commune. However, the number of firms in a commune does not necessarily translate the predominance of an economic sector without an appropriate indication of firm size. Therefore, the number of job-holdings by sector were used as an indication of firm size. The prevalence of the different economic sectors was evaluated and standardized by creating percentages of the total amount of job-holdings in a given commune for every economic sector, it was also arranged into four sectors variables. The primary sector variable relates to the share of agricultural job-holdings in the total population in age of working in a give commune. In a similar fashion, the secondary sector sums the jobholdings of manufacturing and construction industries, whereas the tertiary sector variable comprises of job-holdings in commerce and services industries. Last, the public sector variable refers to public administration job-holdings in a given area. Looking at those different sectors will attempt to provide some information regarding the economic sectors which may or may not be associated with higher or lower precarious forms of employment.

Socio-economic and demographic variables were also used to gain further information on the local supply of labour. For that reason, indicators of the level of skills and gender labour composition in the different communes were used. The data for the following variables was retrieved from the 2008 Population characteristics census of the INSEE.

Two educational variables were generated out of this dataset, the first one regroups the share of individuals in a given commune who have not pursued further education beyond the high-school level, and the second variable represents the share of individuals who have attended a higher education institution for two years or more. Finally the share of women above 15 years old in the total population of a given commune was used as proxy for the gender composition of the local labour market.

Lastly, unemployment was used as a proxy for the overall health of local labour markets and economies and was retrieved from the 2008 INSEE census as well. The 
INSEE data provided the number of unemployed individuals by communes which were then processed into rates of the communal population for standardization purposes.

One major drawback is applicable to all of the aforementioned data. This is the lack of time-series data which could have informed general trends in precarious employment rates have changed over time. The data which will be used therefore only provides a "snapshot" of precarious forms of employment in 2008 rather than an information about the evolution of such types of employment over time.

Finally, the cartographic data was retrieved from the National Geographic Institute (IGN) which provides maps for different administrative units in France. The cartographic data which was designed to be compatible with the INSEE data provided the commune areal units and served as a "spatial canvas" for joining the different aforementioned datasets.

\subsection{Methodology}

\subsubsection{Spatial Statistics Methods}

The localized datasets were used to perform spatial autocorrelation statistical analysis using the GeoDa software. Spatial autocorrelation can be defined as "the correlation of a variable with itself over space" (Burt, Barber and Rigby, p. 544). This method enables one to look at the geographic pattern of values over space and can be understood as follows: a strong pattern of spatial autocorrelation is present when nearby values of a variable will be similar, in contrast, weak spatial autocorrelation is characterized by a random spatial distribution, that is, the absence of a pattern in the spatial arrangement of the values of a variable. Moreover, spatial autocorrelation can be negative or positive, that is to say that a positive spatial autocorrelation implies that similar values of a variable will tend to cluster together, and a negative spatial autocorrelation result will be translated into a cluster of different values of the same variable (Burt, Barber and Rigby, 2009 p.544).

The first statistic applied to examine patterns of spatial autocorrelation in the distribution of precarious employment in France is the Moran's Index (Moran's I) which is formally defined as follows: 


$$
I=\frac{N}{S_{o}} \sum \sum_{i} w_{i j} \frac{\left(x_{i}-u\right)\left(x_{j}-u\right)}{\sum_{i}\left(x_{i}-u\right)^{2}}
$$

Where $N$ represents the number of areas, $x_{i}$ is the value of the variable under consideration for area $i$ and $w_{i j}$ is the spatial weights matrix that defines the structure and the intensity of spatial effects between all pairs of areas in $i$ and $j$ (Cliff et al 1973).

The geographic proximity of spatial units was assessed using the Rook contiguity definition of neighbouring unit. The Rook contiguity is a binary spatial weight that codes neighbouring spatial units as 1 and non contiguous units as 0 (Cracolici 2009).

The Rook contiguity has the characteristic of defining neighbours as units sharing common borders which proves to be appropriate for the use of areal data such as administrative units adapted in this study. Moreover, according to Cracolici (2009), the Rook criterion of contiguity is the most appropriate spatial weights matrix for understanding neighbouring effects in local labour markets.

The results of the Moran's I statistic are interpreted as follows: a positive global Moran's I will indicate positive spatial autocorrelation, whereas a negative global Moran's I will indicate negative spatial autocorrelation. The strength of the spatial relationship is assessed with the value of the global Moran's I. A value of 0 indicates a perfectly random geographic distribution whereas the closer the value is to 1 and -1 the stronger the spatial autocorrelation observed is (Burt, Barber and Rigby, 2009). While these results are particularly interesting for looking at spatial clustering in a general way, they do not indicate where the clustering happens in a given territory. This is why the Local Indicator of Spatial Association (LISA) needs also be applied.

The LISA provides a local value of the global Moran's I and its results are understood in a similar fashion as the previously mentioned global Moran's I. The local Moran's I is specified as follows:

$$
x_{j}<160
$$

Where $z_{i}$ and $z_{j}$ are, respectively, the standard deviation from the mean of observations in area $i$ and $j$ while the summation over area $j$ only accounts for neighbouring units. Indeed, the spatial weights matrix, $w_{i j}$ will be coded as 0 for non neighbouring observations $i j$, and as 1 in the alternative case. (Anselin, L., 1995). 
With regards to the interpretation of the results, the LISA provides a local value of the global Moran's I and its results can be understood in a similar way as that of the global Moran's I. Still, the local Moran's I makes it possible to look at the detailed patterns of geographic distribution of a variable so that the presence and absence of clusters as well as their location can be identified. The geographic proximity of spatial units was assessed using the Rook definition of contiguity that was previously discussed.

The LISA statistics were thus employed to look at the spatial distribution of the precarious forms of employment variables. The results of the LISA computations were then saved into an attribute table. GeoDa assigns codes to each type of clustering for each spatial unit. Non significant results are coded as 0 , high-high results in adjacent units are coded as 1 , low-low results in adjacent units are coded as 2 , low-high results in adjacent units are coded as 3 and finally high-low results in adjacent units are coded as 4 (Anselin, 2003).

Following this, these results were computed using the STATA statistical software package and tabulated to determine which type of clustering was most prevalent for each type of employment.

\subsubsection{Exploring Urban and Rural Locales}

In trying to assess where different clustering typologies are most prevalent, a binary dummy variable was generated to determine which communes could be categorized as urban and rural. The urban and rural binary was assessed using B.H Nicot's (2005) work on the density of urban communes in France which was found to be above 150 inhab. $/ \mathrm{km}^{2}$ in 1999. Yet the average density in France increased by $6.30 \%$ between 1999 and 2008 (INSEE, 2008) so that this figure was revised to account for this change. The decisive density threshold used to generate the urban indicator variable was therefore rounded up to 160 inhab. $/ \mathrm{km}^{2}(150+(150 * 6.3) / 100)$. There are two caveats to consider regarding with this binary variable.

The first is that density is not a precise indicator of the urban and rural status given that some rural areas are denser than 160 inhab. $/ \mathrm{km}^{2}$ and some urban areas have lower densities - this point was previously addressed by Nicot (2005). Indeed, questions pertaining to the different scale of communes come into play and are likely to introduce some errors in this categorization. However, since relevant data was not available under 
the new "urban areas" spatial unit provided by the INSEE, it was decided to keep the 2008 dataset and use this tool as an approximation of the urban or rural status of a commune.

The second issue to keep in mind is that the average density growth between 1999-2008 does not describe the possible differentiated density growth of urban and rural areas. Again, as this is the best indicator of density evolution that could be obtained at the commune level, it was retained. Based on the threshold calculated, this dummy variable codes urban communes $\left(x_{i} \geq 160\right)$ as 1 and rural communes as $0\left(x_{j}<160\right)$ and allows us to approximate the above mentioned typology of communes.

\subsubsection{Bivariate Moran's I}

In an attempt to determine what possible dynamics might be at play behind those exploratory results, several bivariate Global Moran's I were computed using the GeoDa spatial statistics software. The bivariate Global Moran's I relates the value of a variable at one location to that of a second variable in contiguous locations (Anselin, 2003). Each of the four forms of employment were successively assigned respectively to the four economic sector typologies and the socio-economic and demographic variables previously defined. The results can be interpreted in a similar way to that of a normal correlation with the difference that the association between any two variables is of a spatial kind. For example, calculating the bivariate Moran's I of unemployment and parttime work would provide information as to whether the level of unemployment is associated to the level of part-time work in neighbouring cells. This method is therefore particularly useful as it allows one to see which spatial contexts are associated - if they are - to different levels of precarious employment. 


\section{Chapter 4: Results and Analysis}

Before going into the details of the spatial analysis to be addressed in this section, a brief description of the differentiated levels of precarious forms of employment should be provided.

\subsection{Exploratory Results}

\subsubsection{France as a Whole}

Part-time work is the most prevalent form of precarious employment with an average value of $20 \%$ of total employment at the commune level. It is followed by contracts of limited duration which represent an average share of $9.4 \%$ of total employment at the commune level (see Figure 2 in Appendix). Interim and subsidized employment both represent a very small share of total commune employment with a percentage of $1.85 \%$ and $1.08 \%$ respectively.

This points to a possible statistical problem with the following steps in the analysis. Indeed, not only are both interim and subsidized employment present at very low levels, but their respective standard deviation (s.d) is of approximately 1.87 which is substantially lower than that of part time work $(\mathrm{s} . \mathrm{d}=6.81)$ and contracts of limited duration $(\mathrm{s} . \mathrm{d}=5.83)$. This low standard deviation for interim and subsidized work means that the share of both types of employment in total employment will not vary substantially across communes. In other words, it is not expected that levels of interim and subsidized employment will display a particular spatial pattern since the level of both types of employment is not particularly differentiated across the communes. Still, it is also worth mentioning that the s.d remains an aggregate summary measure of dispersion and that there still remains a possibility that spatial statistics tool will reveal a geographic pattern to the distribution of Interim and subsidized employment. Certainly, because of their low s.d, their potential geographic distribution still would not be expected to be of the same magnitude as both PT or CLD employment forms.

\subsubsection{At the Regional Level}

Moving from those more aggregate indicators of precarious employment, assessing the differentiated geographic distribution of precarious forms of employment 
can be achieved in multiple ways. As discussed in the methodology, spatial statistics are used to gauge whether the spatial distribution under study is not random and indeed follows a pattern. Still, much can be observed from a more exploratory standpoint. Comparing average shares of precarious forms of employment in total employment for each of the 24 French regions certainly provides the beginning step of an understanding of the geography of the phenomenon.

As can be observed in Figures 3 and 4 (see Appendix) CLD and PT work follow a somewhat similar pattern across regions with the shape of the distribution of shares across regions appearing to be fairly consistent. Both the Languedoc-Roussillon and Provence - Alpes Côte d'Azur regions, for example, have a high share of precarious CLD and PT forms of employment. The same can be said for the Champagne-Ardenne and Midi-Pyrénnées areas. Interim and subsidized employment forms display a drastically different pattern and do not seem to take on similar values (see Figure 3 and 4 in Appendix). The one consistent result is that the Ile de France region - in which Paris and its agglomeration are located - has lower shares of the four types of precarious employment.

Given the regional patterns observed above, it is not surprising that the Pearson's correlation coefficient reveals a positive and significant relationship between PT and CLD precarious forms of employment (see Figure 4 in Appendix). The correlation coefficients among employment types are either low, +0.17 between subsidized employment and PT work, or negligible, as with the relationship between interim and PT work. Based on those results it cannot be expected that overall - with the exception of the CLD and PT forms of employment - high concentrations of one form of precarious employment would be associated to high concentrations of another precarious employment type in any commune. This is an important finding as it hints at the fact that, for the most part, each precarious form of employment is likely to display a different spatial distribution.

\subsubsection{An Urban/Rural divide?}

Differentiating between urban and rural areas provides a different and relevant approach to observing the territorialized distribution of precarious forms of employment in France. Indeed, as was observed earlier, the Parisian agglomeration appeared as a cold 
spot for part-time work and contracts of limited duration. It is therefore important to factor in whether a commune is rural or urban and see whether this differentiation informs a spatial understanding of precarious employment. The urban/rural dummy variable was used to account for this. Here, it is worth noting that Nicot's (2005) original work identified $\mathrm{n}=5954$ communes as urban based on a density threshold calculated using the 1999 Population Census. The number of urban communes found based on the updated density threshold for the 2008 Population Census was of $n=5201$, which represents about $87 \%$ of the Nicot's number of urban communes. These figures are inline with previous research and allow one to provide a general picture of the difference between urban and rural areas with regards to their spatial distribution of precarious forms of employment.

Figure 5 (see Appendix) provides the mean and standard deviation of the four precarious employment variables for urban and rural communes. A two-group difference of means t-test was conducted to test whether the average shares of precarious forms of employment across urban and rural communes were different. All shares of precarious forms of employment are considered statistically different at a $0.05 \%$ level of significance. Furthermore, the rural average shares of precarious employment were statistically superior to their urban equivalents with the exception of interim work. Indeed, interim displayed statistically higher-levels in urban communes than in rural communes. Still, three out of four precarious employment forms were more highly concentrated in rural areas comparatively to urban areas. Of course, average shares are not particularly telling of the variegated levels of precarious form across urban and rural communes as one would expect very different socio-economic and demographic profiles across the entire French territory. In trying to understand this differentiation, the standard deviation provides a general indicator of the dispersion of shares of precarious employment across urban and rural groups. What is striking about those results is that, in all in cases, the standard deviation of shares of precarious employment in rural areas is at the very least twice that of urban areas. This goes to show that rural areas encompass more differentiated levels of precarious employment than urban areas. This can be partly attributed to the overall higher number of rural observations $(n=31387)$ compared to urban communes $(\mathrm{n}=5201)$, even though the lower variance in urban areas may indicate that on the whole, urban areas are less targeted by the phenomenon of precarious 
employment than rural areas. In other words, those results reveal that a geographic pattern may be at play in the distribution of precarious employment. A problem with this approach is that it remains aggregated - which is not particularly indicative of the differentiated local distribution of precarious employment. Moreover, it imposes a binary restriction on the potential geographies of those forms of employment which could in turn dissimulate other spatial patterns at play.

The next step in this research is therefore to assess the spatial distribution of precarious forms of employment using spatial statistics tools in an attempt to deconstruct and disaggregate the geographies of precarious employment and reduce specification biases. In doing so, first, the global Moran's I for each type of employment will be described to assess whether each type of precarious employment displays some form of spatial clustering. Following this, a description of the dominant spatial arrangements for each employment type will be presented.

\subsection{Assessing the Spatial Patterns of Precarious Employment}

\subsubsection{Aggregated Indicators of Spatial Autocorrelation (Global Moran's I)}

Figure 6 (see Appendix) shows the Moran's I coefficients for all four different forms of precarious employment. The global Moran's I values vary indicating that various forms of precarious employment display different spatial patterns. Before delving into the specifics of each, it is important to mention that all the results presented below were statistically significant with a p-value of 0.001 .

The strongest spatial pattern that can be observed is that of the CLD (contract of limited duration) and PT (part-time) employment. Both show a Moran's I value of above +0.3 which is an indication of positive spatial autocorrelation. Using the example of CLD, this result can be understood as follows: about $30 \%$ of the share of CLD in a given commune $i$ can be explained by the level of precarious forms of employment in neighbouring communes $j$. Furthermore, the Moran's I values are both positive which suggests that the dominant form of clustering is one of high values of precarious PT or CLD surrounded by respectively high values of PT or CLD.

The two other kinds of precarious employment both have a smaller Moran's I which indicates that there is a weaker spatial pattern in their respective cases. Interim employment for example, displays a Moran's I value of 0.14 and subsidized employment 
(SE) a very low Moran's I of 0.08. Moreover, since both values are statistically significant it can tentatively be said that each of the two variables are not strongly spatially autocorrelated so that a spatial analysis of both variables may not be as revealing as it would be for CLD and PT variables. This might be in part due to the low variance of both subsidized employment and interim variables. However, the two first variables mentioned, CLD and PT both indicate that a certain spatial pattern is at play. The following sub-section attempts to characterize the spatial pattern of each precarious form of employment. The LISA maps and outputs relevant to each are discussed in turn.

\subsubsection{Local Indicators of Spatial Autocorrelation (LISA)}

The LISA maps generated using the GeoDa software reveal interesting spatial patterns to the distribution of precarious forms of employment. One of the most striking maps is that of part-time work. In the context of this employment form, a very clear cold spot is observed in the Parisian agglomeration indicating that this entire area is characterized by lower shares of part-time work in contrast with the surrounding communes (see Figure 7 in Appendix). A similar pattern can be observed in the LISA map for CLD work though to a lesser extent (see Figure 8 in Appendix). An interesting feature of the distribution of CLD work is the hot spots in the Alpes and Pyrénnées regions. This can tentatively be attributed to the touristic nature of those areas and the associated concentration of seasonal work which are categorized as CLD work. Part time work also featured hot spots in the southern half of France, particularly towards the Alpes and Pyrénnées regions though it is not clear if it can be associated to seasonal work (See Figure 7 in Appendix). This goes to show would that it would have been particularly interesting to have seasonal data in order to investigate the effects of tourism and seasonal job dynamics on the geography of precarious employment.

Subsidized and Interim work both display a somewhat different geography (see Figures 9 and 10 in Appendix), where the Midi-Pyrénnées region shows a concentration of low values of interim work; in contrast, the same region had been identified as a zone of high concentration of contracts of limited duration. What both interim and subsidized employment share in common is that their geographic distribution appears less condensed than that of part-time work, and to a lesser extent that of contracts of limited duration. It is rather clear that upon looking at the different LISA maps, each type of precarious 
employment has a differentiated spatial distribution, even though certain commonalities can be observed. Considering this, instead of doing a doing a local profile of each cluster following the approach adopted by Ribardière (2005), systematic statistical tools are used to decipher the forces at play in the localization of precarious employment in the last section of this chapter.

Yet, before going into the why behind the localization of precarious employment, it will be the attempt of this research attempts to gauge which form of clustering is dominant across each employment variable, i.e. whether low values are situated next to other low values or high values situated next to other high values. As mentioned earlier, the GeoDa spatial statistics software assigns a number to each type of spatial clustering for each spatial unit or observation. This information was used to assess which spatial clustering was dominant across employment forms as well as across urban and rural communes (see Figures 11 and 12 in Appendix).

\subsubsection{A Typology of Spatial Patterns}

With respect to precarious forms of employment in general, what is striking is the high number of non-significant clusters, which are shown as 0s in the dataset (see Figure 12 in Appendix). Indeed, non-significant clusters follow a range spanning from $75 \%$ to $86 \%$ of the total number of observations $(n=36588)$ for each employment type. In spite of this, a large number of observations, in absolute terms, still display some form of spatial clustering. The dominant type of spatial clustering across all forms of employment is that of low values surrounded by other low-values, which represents almost $13 \%$ of all observations for PT and $10 \%$ for CLD. This reveals that there is some similarity in precarious employment levels among neighbouring units. The second most prevalent form of clustering is that of high values surrounded by other high-values which is also sign of similarity among neighbouring units. Among PT employment forms, $8 \%$ of communes are in high-clusters. The same figure for CLDs is $7 \%$. The predominance of those two forms of clustering is also valid for interim and subsidized work. In other words, the predominant spatial association among contiguous communes is one of positive spatial autocorrelation.

Tabulating the spatial distribution of precarious form of employment informs us of two things. First, that a pattern in the spatial distribution of precarious employment 
emerges, and that this pattern is predominantly one of pockets or clusters of similar values across the French territory. That is to say that the value of precarious forms of employment in one spatial unit will, for certain observations, be associated to that of the neighbouring units. These can be understood as hot-spots, in the case of the spatial association of high values to other high values, or cold spots where low values are associated to other low values. Second, a third set of observations shows indications of a clustering of different values, these areas will be referred to as dichotomous areas. Based on those results, the next step will be to assess where those areas of dichotomy and of similarity are situated and what may explain this spatial pattern.

\subsubsection{Another urban/rural divide in clustering typologies?}

Using the urban/rural binary dummy variable that was previously mentioned provides a finer grained picture of the spatial distribution of precarious forms of employment in France (Figure 12). As will be discussed, once again a divide emerges between the results for part-time work with contracts of limited duration as one group, and subsidized employment with interim work as another group. In contrasting urban and rural spatial patterns of precarious forms of employment, two results stand out (with regards to TP and CLD work). First, overall, urban communes have a higher share of low-low clusters than rural areas. Second, the predominant form of spatial clustering is still that of low-low values in rural areas; yet, this form is only slightly more prevalent than that of high-high clusters. This is rather striking with the example of the spatial distribution of part-time work. In urban communes the undisputed majority of clusters - besides the non-statistically significant ones - were low-low clusters ( $20 \%$ of observations) compared to a very small share of high-high clusters ( $1 \%$ of observations). In rural communes the divide between low-high and high-high clusters was much smaller with only a 1.88 percentage point of difference.

The second group presents a different pattern of spatial distribution. To begin with, the urban and rural divide in clustering forms is not as sharp as witnessed with the first group. Indeed, using the example of subsidized employment, in urban communes, low-low clusters were only more prevalent than high-high clusters by +1.48 percentage point. In the context of rural communes low-low clusters were only more prevalent than high-high clusters by +1.88 percentage point. On the other hand, the prevalence of low- 
high clusters does not apply to interim work in urban communes as high-high clusters were more prevalent by +0.77 percentage point. In the case of subsidized employment in rural communes, high-low clusters were the second most prevalent form of spatial clustering after low-high clusters and before high-high clusters (only by 0.05 percentage point in this instance).

\subsection{Discussion}

These results follow some of the spatial models described by Antonine Ribardière (2005). Recall that Ribardière's (2005) analysis focused on the Parisian urban agglomeration such that her findings only account for the diverse geographic distributions of social precarity in this specific geographic context using infra-urban spatial units. Still, two of the models that she defines are particularly relevant to the above-mentioned results.

The first model that she discusses is the "socio-spatial mosaic model" whereby levels of precarity are vastly heterogenous across spatial units and do not seem to follow a particular pattern. The communes that fit into that model are seen as very diverse from a socio-economic standpoint. This lack of pattern is discernible across all of the results discussed previously and evidenced by the dominant share of non-significant clustering types which represent at least $75 \%$ of observations for each form of employment researched.

The second model is called "the divided urban space model" which could be renamed "the divided social space model" since the results presented here go beyond urban areas solely. In this model, some clearly discernible pockets of social precarity tend to straddle more well off areas. This model does not account for the results found above since both high-low and low-high cluster forms were found to be least prevalent in the LISA outputs.

The socio-spatial model, on the other hand, appears to fit the results found in this research much better. As previously mentioned, low-low and high-high clusters were found to be the most prevalent forms of spatial clustering of precarious employment. This is indicative that a certain segregation is occurring in the French territory with regards to precarious employment. What is interesting is that due to the low share of low-high and 
high-low cluster forms, those cold-spots and hot-spots for precarious employment seem to be seldom in contact.

This pattern raises issues from a social and political standpoint, as Mansel and Heitmeyer (2010) have observed, since contiguous areas of social dissimilarity are likely to generate discontent and frustration for the underprivileged. On the other hand, Ribardière (2005) stresses that the contiguity of socially differentiated areas may constitute a resource for the underprivileged especially with regards to sharing public infrastructures such as schools. However, some have some also contend that the urban and social segregation - in which precarious employment plays an important role present in French society could have contributed to causing the urban riots of November 2005 (Kokoreff et al, 2007). It is difficult to determine whether the direct spatial contact between deprived and more well-off areas could have contributed to this event. Indeed, the knowledge of the socio-spatial segregation at play in France, rather than its experience may have also caused some of the frustrations behind the riots. It is clear, however, that Ribardière's (2005) argument that deprived areas - understood as suffering from social precarity - may benefit from being close to more well-off areas is challenged by the results found here. Indeed, the spatial segregation of precarious employment prevents those potential benefits of geographic proximity and may further entrench precarious employment in certain locales in the absence of public intervention.

With regards to the underlying explanations of the model, Ribardière (2005) attributes this pattern in the Parisian agglomeration to the higher concentration of social housing in specific areas and the industrial legacy of certain areas. This interpretation is certainly not fully applicable to the whole French territory as each region has its own individual socio-economic profile, economic structure and history. However, the emphasis that she provides on the different locales of precarity in the Parisian agglomeration seems to indicate that a range of variables may potentially explain the localization of precarity in given areas.

This is why, after attempting to answer how, where and to what extent precarious forms of employment follow a geographic distribution, the next step of this research is to understand why precarious forms of employment are localized where they are. In an attempt to do so, bivariate Moran's I calculations are examined by pairing a selected range of variables to the four precarious forms of employment variables. 


\subsection{Exploring the Localization of Precarious Employment}

Each precarious form of employment variables was paired with eight variables in Figure 13 (see Appendix). Those variables were selected in an attempt to account for some of the economic and demographic characteristics of each communes. They include economic sectors, local unemployment rates, the net average fiscal revenue in each communes, and lastly the proportion of individuals with and without university education - where university education is defined as at least two years of higher education. A bivariate Moran's I is computed for each combination of two variables in order to assess the spatial correlation of any of the two pairs selected. The figures can be interpreted similarly to that of a regular Pearson's correlation coefficient.

Upon first glance at the results, what is striking is that few variables seem to be strongly correlated, either negatively or positively. The strongest correlation coefficients are in the range of +0.06 and above. The combination of variables that were found to be most positively correlated were that of individuals without university education and the different types of precarious employment. This goes to say that, to some extent, communes with higher shares of precarious employment are also characterized by higher shares of non-university educated populations in contiguous areas. The negative correlation between precarious forms of employment and university-educated individuals seems to indicate that the opposite claim stands as well. On a different note, according to previous studies on the topic (Givord, 2005), the age of degree holders may affect the form of employment to be occupied, as the youth are defined as a population at risk for precarity. A differentiated pattern may have appeared if this had been included in this research.

The economic sectors variables were not particularly correlated with the presence of precarious forms of employment. The fact that secondary and tertiary sectors both display a low negative correlation to precarious employment is also indicative that the predominance of one sector of activity in an area is not tied to the presence precarious employment in other contiguous areas. Two other economic variables indicate a more consistent correlation to precarious forms of employment, unemployment and net revenue. The positive correlation between precarious employment and unemployment shows that the presence of precarious employment in an area is associated with higher levels of unemployment in contiguous areas. On the other hand, the negative correlation 
between net revenue and precarious employment indicates that areas of precarious employment neighbour areas of lower revenue.

The previous results seem to indicate that the socio-economic variables often found in the literature on the topic are more closely associated to the presence of precarious employment than the sectoral variables that were introduced in this research. However, the female population variable was negatively associated to precarious employment which runs against previous literature on the topic and general assumptions about the phenomenon of precarious employment (Maruani, 2004).

Nonetheless, in general terms, the correlation coefficients that were found in this research remain at low levels. In the case of both part-time work and contracts of limited duration, some relatively high and positive Moran's I were found, which indicate that there is a positive spatial association to precarious employment levels for each of the types of employment. The results found in this section certainly help in disentangling some of the reasons behind this clustering of precarious employment across the French territory, yet only provide a very partial understanding of the geographic distribution of the phenomenon. Understanding the geography of precarious employment will therefore require a consideration of other economic, socio-economic and demographic variables. 


\section{Chapter 5: Conclusion}

Precarious forms of employment have been steadily increasing since the 1980s in the France and multiple social and health shortcomings have been associated to the phenomenon. It is therefore no surprise that some have welcomed this upward trend with a critical eye. However, little research deals with precarious employment as a localized issue, whereby the importance of spatial context plays a role in determining observed levels of precarious employment across very different locales. The goal of this research was to address this gap in the literature through exploratory spatial data analysis.

First, in answer to the question: "is there a spatial pattern to the distribution of precarious employment" it was found that a spatial pattern is at play for part-time and contracts of limited duration. Interim and subsidized work, however, seem to display much weaker spatial patterns.

The second question that was addressed related to where precarious forms of employment were localized. Here, it was found that urban areas displayed statistically lower levels of precarious employment for part-time work and contracts of limited duration than rural areas, whereas the opposite situation was found for both Interim and subsidized employment.

The third question that was discussed addressed the issue of how precarious forms of employment were distributed across space. Two dominant spatial patterns were identified following either a cold-spot or hot-spot typology across most forms of precarious employment. Urban areas showed a more cut and dry predominance of the cold-spot typology in contrast to other spatial pattern typologies. Drawing from Mansel and Heitmeyer (2010) and Ribardière's (2005) works, these findings can be tied to the socio-spatial problems which are observed in France. Particularly, the cold-spot and hotspots identified earlier may reinforce the existing social-segregation, and participate in the social discontent and frustrations which had culminated into the riots of 2005 .

Lastly, the spatial association of precarious employment types to that of various economic and socio-economic variables was assessed to gauge why precarious employment was concentrated in certain areas and not in others. Few interesting results were found here. Generally speaking, socio-economic variables were determined to be 
more strongly associated to precarious employment - e.g. educational attainment variables, rather than the economic sectors variables. 


\section{Bibliography}

\section{Literature}

Anselin, L. (1995). Local indicators of spatial association -LISA. Geographical analysis, vol. 27(2), pp. 93-115.

Anselin, L. (2003). An introduction to spatial autocorrelation analysis with Geoda.

Retrieved from : http://geodacenter.asu.edu/pdf/geodaGA.pdf

Aragon, Y. Haughton, D., Haughton, J. Leconte, E. Malin, E., Ruiz-Gazen, A., ThomasAgnan, C. (2003). Explaining the pattern of regional unemployment: The case of the Midi-Pyrénées region. Papers in regional science, vol. 82, pp. 155-174.

ATTAC, (2006). CDD, Intérim, CNE, CPE : Quelles alternatives à la précarité et au chômage ?. Retrieved from : http://www.france.attac.org/articles/cdd-int-rim-cne-cpequelles-alternatives-la-pr-carit-et-au-ch-mage

Burtt, J. E., Barber, G. M. (2009). Elementary statistics for geographers. New York, N.Y : The Guilford Press.

Coe, N. M., Johns, J., Ward, K. (2009). Managed flexibility : Labour regulation, corporate stratégies and market dynamics in the swedish temporary staffing industry. European urban and regional studies, vol. 16(1), pp. 65-85.

Concialdi, P. (2006). La France précarisée: un état des lieux. In La Découverte (Eds.), Travail fléxible, salariés jetables (pp. 17-20). Paris, France.

Cottrell, M., Letremy, P., Macaire, S., Meilland, C., Michon, F. (2002). Le temps de travail des formes particulières d'emploi. Économie et statistique, 352-353, pp. 169-189.

Cracolici, M. F., Cuffaro, M., Nijkamp, P. (2008). A spatial analysis on Italian unemployment differences. Statistical methods applied, vol. 18, pp. 275-291.

Dörre, K., Kraemer, K., Speidel, F. (2006). The Increasing Precariousness of the Employment Society: Driving Force for a New Right Wing Populism?. International journal of action research, vol. 2, pp. 98-128.

François, J-C., Ribardière, A. (2004). Qu'apporte l'échelon infracommunal à la carte des inégalités de richesse en Ille-de-France?.M@ppemonde,vol.3,pp.1-8. Retrieved from :

http://mappemonde.mgm.fr/num3/articles/art04305.html

Gialis, S., Karnavou, E. (2009). Dimensions of atypical forms of employment in Thessaloniki, Greece. International journal of urban and regional research,vol. 32(4), pp. 882-902. 
Givord, P. (2005). Formes particulières d'emploi et insertion des jeunes. Économie et statistique, 388-389, pp. 129-143.

Hélardot, V. (2005). Précarisation du travail et de l'emploi : quelles résonances dans la construction des expériences sociales ?. Empan, vol. 60, pp. 30-37.

INSEE (2011). Contrat aidé. Retrieved from:

http://www.insee.fr/fr/methodes/default.asp?page=definitions/contrat-aide.htm

INSEE (2008). Évolution et structure de la population. Retrieved from :

http://www.recensement.insee.fr/chiffresCles.action?zoneSearchField=FRANCE\&codeZ one $=1-F E \&$ idTheme $=3$

INSEE (2011). Formes particulières d'emploi. Retrieved from :

$\mathrm{http}$ //www.insee.fr/fr/methodes/default.asp?page=definitions/forme-particuliereemploi.htm

Korkoreff, M., Steinauer, O., Barron, P. (2007). Les émeutes urbaines à l'épreuve ds situations locales. SociologieS. Retrieved from :

http://sociologies.revues.org/254?\&id=254

Les manifestations anti-CPE du 28 mars en France. (2006, March 29th). Le Monde.

Retrieved from :

http://www.lemonde.fr/societe/infographie/2006/03/28/les-manifestations-anti-cpe-du-28mars-en-france_755523_3224.html

Mathieu, N. (1997). Pour une nouvelle approche spatiale de l'exclusion sociale. Strates, vol. 9, Retrieved from : http://strates.revues.org/612

Mansel, J., Heitmeyer, W. (2010). Precarity, segregation, and poverty in the social space - overview of the research status. Deutches institut für urbanistik. Retrieved from : http://www.difu.de/publikationen/precarity-segregation-and-poverty-in-the-socialspace.html

Maruani, M. (2004). Activité, précarité, chômage : toujours plus ?. Presse de sciences Po, Revue de l'OFCE, vol. 90, pp. 95-115.

McDowell, L., Christopherson, S. (2009). Transforming work : new forms of employment and their régulation. Cambridge journal of regions, economy and society, vol. 2, pp. 335-342.

Nicot, B. H. (2005). Urbain-rural : de quoi parle-t-on?. Sirius-Université Parix XII.

Oberhauser, A. M. (1990). Social and spatial patterns under fordism and flexible accumulation. Antipode, vol. 22(3), pp. 211-232.

Observatoire des inégalités (2010). Le temps partiel subi en France. Retrieved from : http://www.inegalites.fr/spip.php?article410\&id_mot=89

Patacchini, E., Zenou, Y. (2007). Spatial dependence in local unemployment rates. Journal of Economic Geography, vol. 7, pp. 169-191. 
Paugam, S. (2000). Le salarié de la précarité. Broché (Eds.), Paris, France.

Peck, J. \& Tickell, A. (2002) Neoliberalizing space. Antipode, Vol 34 (3), pp. 1-25.

Perez, C., Thomas, G. (2005). Trajectoires d'emploi précaire et formation continue. Économie et statistique, vol. 388-389, pp. 107-127.

Ribardière, A. (2005). Précarité sociale: quand les mailles s'en mêlent. Doctoral dissertation, Université Paris 1, April $22^{\text {nd }} 2006$.

Rolfsen, L., Segnini, P. (2001). Entre le chômage et l'engrenage des emplois précaires. Travailler, Vol. 6, pp. 129-146.

Simonin, B. (2004). Territoires de l'emploi. Projet, vol. 278, pp. 83-86.

Tovar, E. (2011). Ségrégation et formes d'emploi à Paris. Revue d'économie régionale et urbaine, vol. march 2010/1, pp. 111-134.

Tsianos, V., Papadopoulos, D. (2006). Precarity : a savage journey to the heart of embodied capitalism. European institute for progressive cultural policies. Retrieved from : http://eipcp.net/transversal/1106/tsianospapadopoulos/en

Tuschszirer, C. (2005). Les différentes approches de la précarité de l'emploi en Europe, au Japon et aux Etats-Unis. Chroniques internationales de l'IRES, vol. 97, pp. 23-32.

Waite, L. (2009). A place and space for a critical geography of precarity ?. Geography compass, vol. 3(1), pp. 412-433.

Zenou, Y. (2011). Search, wage posting and urban spatial structure. Journal of economic geography. Vol. 11, pp. 387-416.

\section{Data}

\section{a) Statistical data}

INSEE (2008). Caractéristiques de l'emploi, France. Retrieved from :

$\mathrm{http}: / / \mathrm{www}$.insee.fr/fr/bases-de-donnees/default.asp?page=statistiques-locales/form-condemp.htm

INSEE (2008). Chiffres clés : Caractéristiques des entreprises et des établissements, France. Retrieved from :

http://www.insee.fr/fr/bases-de-donnees/default.asp?page=statistiques-locales/carac-entetab.htm

INSEE (2008). Chiffres clés : Diplômes - formation, France. Retrieved from : http://www.insee.fr/fr/bases-de-donnees/default.asp?page=statistiques-locales/diplform.htm 
INSEE (2008). Chiffres clés : Famille - situation matrimoniale, France. Retrieved from : http://www.insee.fr/fr/bases-de-donnees/default.asp?page=statistiques-locales/couplefam-menage.htm

INSEE (2010). Chiffres clés : Résumé statistique, France. Retrieved from :

http://www.insee.fr/fr/themes/detail.asp?reg_id=99\&ref_id=base-cc-resume-stat

\section{b) Cartographic data}

IGN (2011). GEOFLA, France. Retrieved from :

http://professionnels.ign.fr/ficheProduitCMS.do?idDoc=5323861 


\section{Appendix}

Figure 1. Hierarchy of French administrative units in descending order of aggregation in 2012 (including French overseas departments)

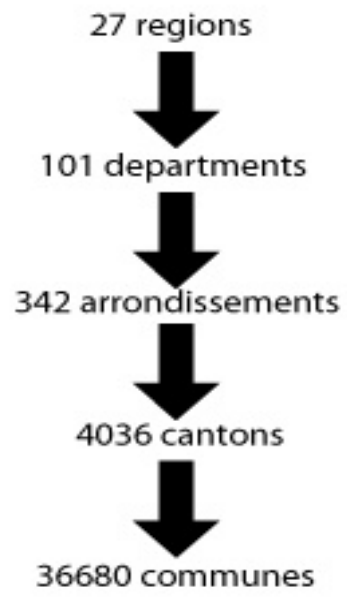

Figure 2. Summary statistics of precarious employment in France

\begin{tabular}{|c|c|c|c|c|}
\hline & PT & CLD & Interim & Subsidized \\
\hline Mean & 20.15061 & 9.376717 & 1.853336 & 1.077403 \\
\hline Variance & 46.47633 & 33.94578 & 3.516427 & 3.433269 \\
\hline Std. deviation & 6.817355 & 5.826301 & 1.875214 & 1.852908 \\
\hline
\end{tabular}


Figure 3. Regional levels of precarious forms of employment
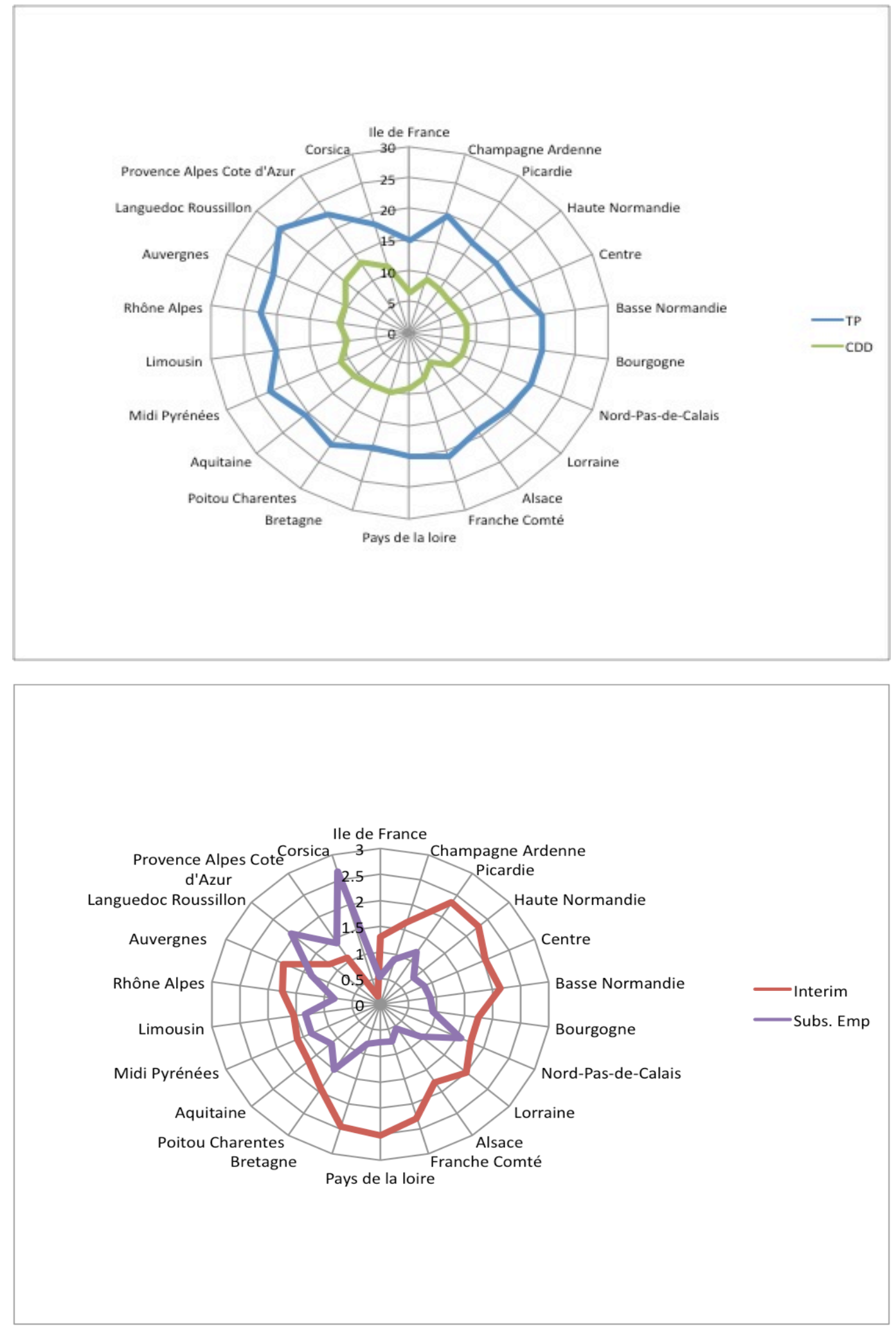

note: CDD stands for CLD. 
Figure 4. Pearson's correlation coefficients among employment types (at a $0.05 \%$ level of significance).

\begin{tabular}{|l|l|l|l|l|}
\hline & PT & CLD & Interim & Subsidized \\
\hline PT & & 1 & & \\
\hline CLD & & & 1 & 1 \\
\hline Interim & $0.3162^{*}$ & $-0.0919^{*}$ & 1 \\
\hline Subsidized & $-0.0776^{*}$ & $0.1678^{*}$ & $0.0566^{*}$ & 0.0006 \\
\hline
\end{tabular}

Figure 5. Mean and standard deviation of the four precarious employment variables for urban and rural communes.

\begin{tabular}{|c|c|c|c|c|}
\hline & PT & CLD & Interim & Subsidized \\
\hline Mean Urban & 18.28619 & 8.298234 & 1.959321 & 0.9960926 \\
\hline St. deviation Urban & 3.30191 & 3.48185 & 1.17686 & 0.81558 \\
\hline Mean Rural & 20.46 & 9.555427 & 1.835773 & 1.090876 \\
\hline Std. deviation Rural & 7.19028 & 6.11045 & 1.96660 & 1.97248 \\
\hline $\begin{array}{l}\mathrm{T} \text {-test result }(0.05 \% \\
\text { significance })\end{array}$ & Different: $\mathrm{R}>\mathrm{U}$ & Different: $\mathrm{R}>\mathrm{U}$ & Different: $\mathrm{R}<\mathrm{U}$ & Different: $\mathrm{R}>\mathrm{U}$ \\
\hline
\end{tabular}

Figure 6. Global Moran's I values and pseudo p-values for each employment form.

\begin{tabular}{|c|c|c|c|c|}
\hline & PT & CLD & Interim & Subsidized \\
\hline Global Moran's I & 0.3036 & 0.3253 & 0.1412 & 0.0871 \\
\hline Pseudo P-value & 0.001 & 0.001 & 0.001 & 0.001 \\
\hline
\end{tabular}


Figure 7. LISA map of part-time work in France.

\section{LISA Map of Part-Time Work in France}

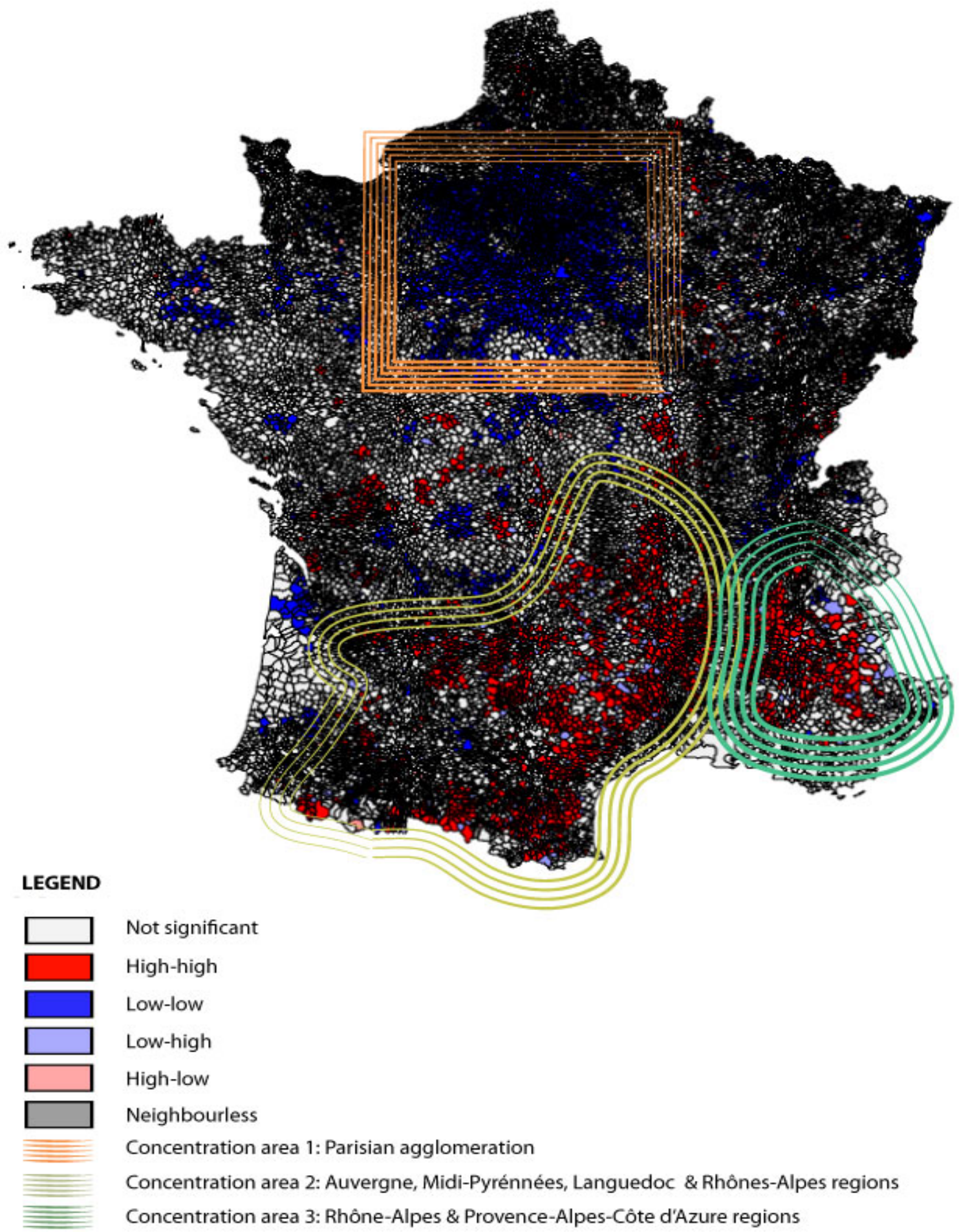


Figure 8. LISA map of contracts of limited duration in France

LISA Map of Contracts of Limited Duration in France

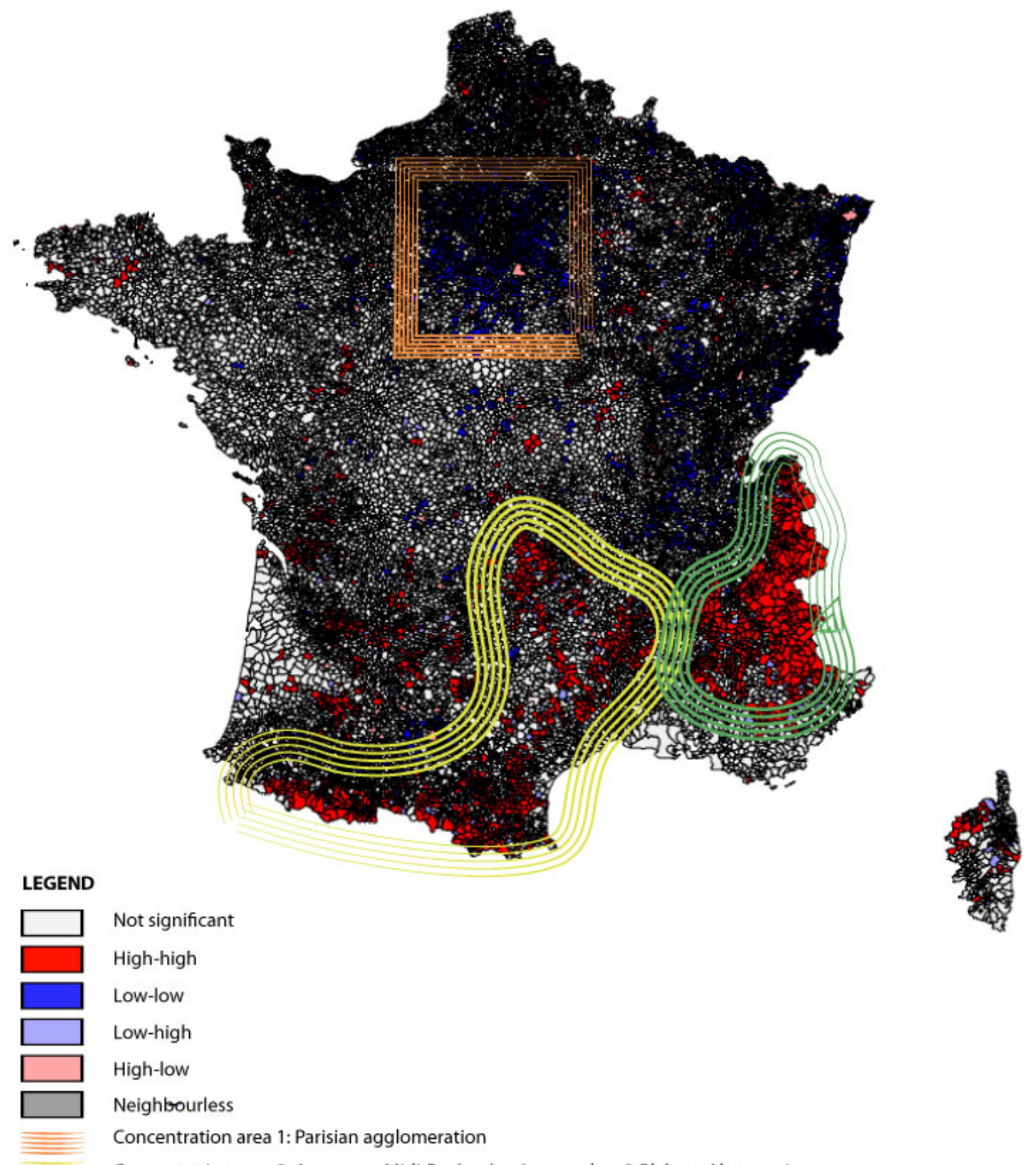

Concentration area 2: Auvergne, Midi-Pyrénnées, Languedoc \& Rhônes-Alpes regions

Concentration area 3: Rhône-Alpes \& Provence-Alpes-Côte d'Azure regions 
Figure 9. LISA map of Interim work in France

\section{LISA Map of Interim Work in France}

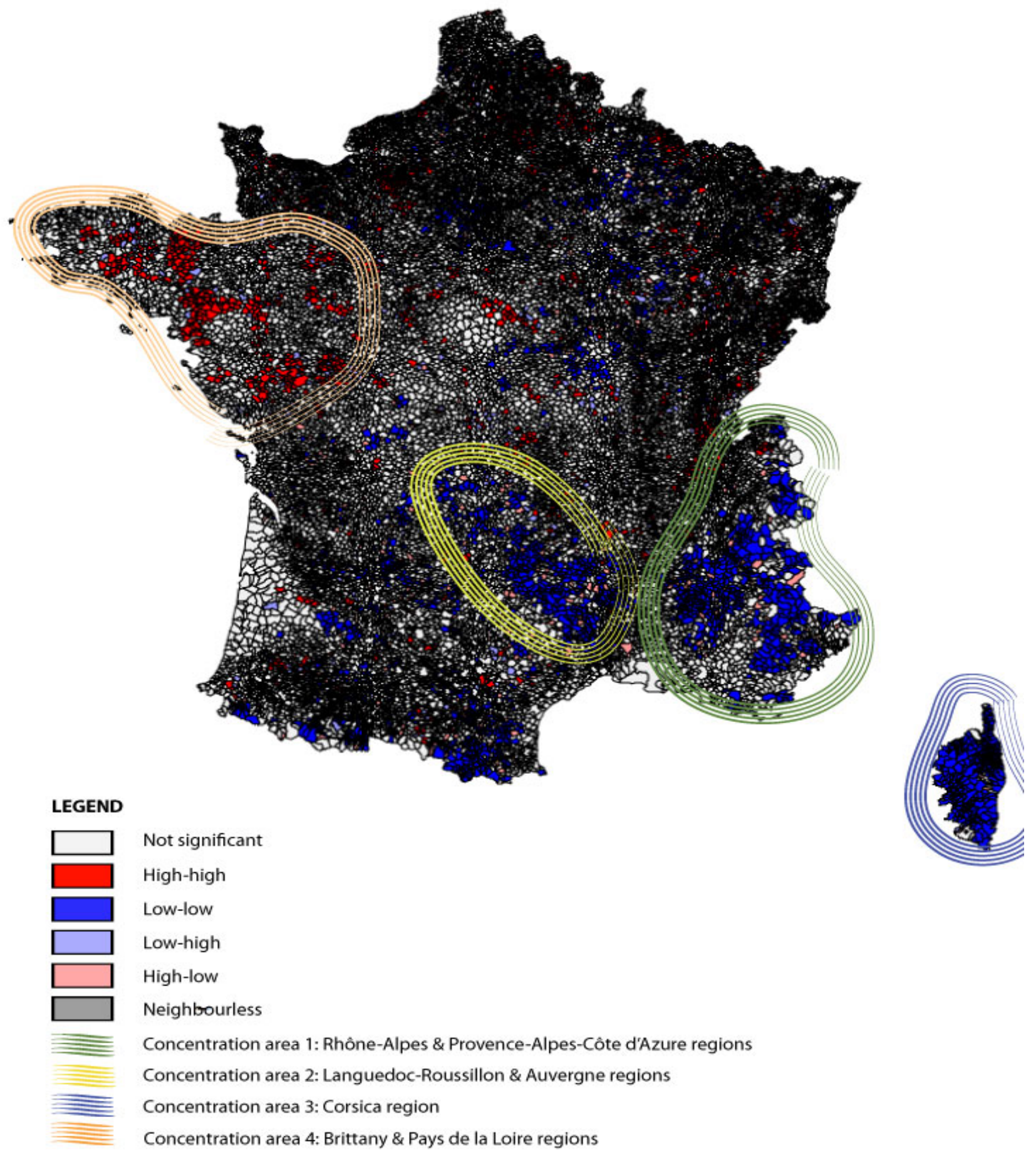


Figure 10. LISA map of subsidized employment in France

\section{LISA Map of Subsidized Employment in France}

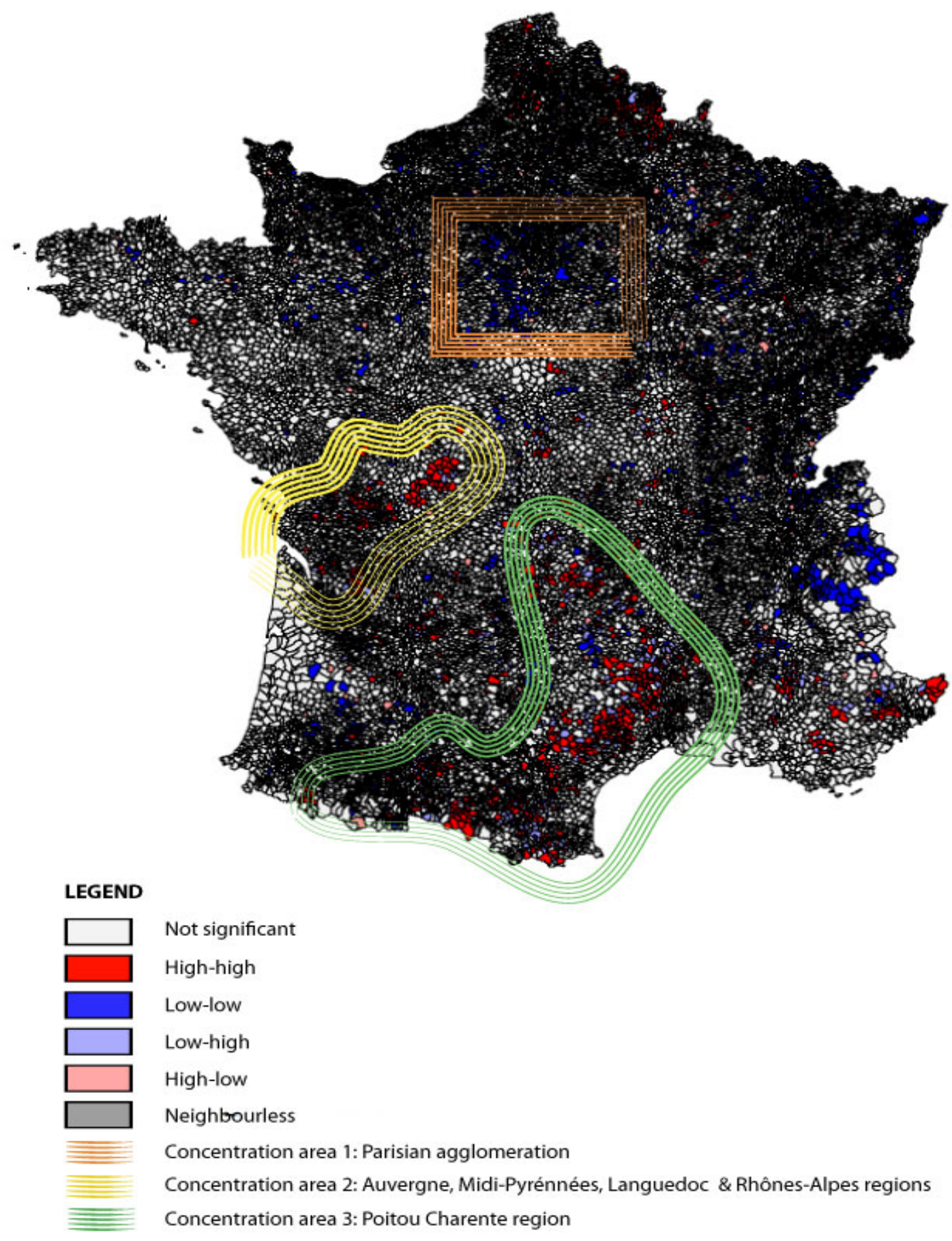


Figure 11. LISA outputs for France as a whole computed as shares of cluster types (\%).

\begin{tabular}{|l|r|r|r|r|}
\hline Percentage of total cluster types (\%) & PT & \multicolumn{2}{l|}{ Subsidized } \\
\hline Non significant clusters & 74.85 & 79.46 & 80.51 & 86.41 \\
& $(27387)$ & $(29071)$ & $(29457)$ & $(31616)$ \\
\hline High-high & 8.41 & 6.85 & 5.57 & 3.46 \\
\hline Low-low & $(3076)$ & $(2505)$ & $(2038)$ & $(1266)$ \\
\hline High-low & 12.77 & 10.2 & 8.94 & $(1935)$ \\
\hline & $(4672)$ & $(3731)$ & $(3271)$ & 3.29 \\
\hline Low-high & 2.37 & 1.88 & 3 & $(1197)$ \\
\hline
\end{tabular}

Note: The absolute number of cluster types for each employment form appears in parenthesis.

Figure 12. LISA outputs for urban and rural communes, computed as shares of cluster types (\%).

\begin{tabular}{|c|c|c|c|c|c|c|c|c|}
\hline $\begin{array}{l}\text { Percentage of total } \\
\text { cluster types (\%) }\end{array}$ & $\begin{array}{l}\text { PT } \\
\text { Urban }\end{array}$ & PT Rural & $\begin{array}{l}\text { CLD } \\
\text { Urban }\end{array}$ & $\begin{array}{l}\text { CLD } \\
\text { Rural }\end{array}$ & $\begin{array}{l}\text { Interim } \\
\text { Urban }\end{array}$ & $\begin{array}{l}\text { Interim } \\
\text { Rural }\end{array}$ & $\begin{array}{l}\text { Subsidized } \\
\text { Urban }\end{array}$ & $\begin{array}{l}\text { Subsidized } \\
\text { Rural }\end{array}$ \\
\hline $\begin{array}{l}\text { Non significant } \\
\text { clusters }\end{array}$ & $\begin{array}{r}78.25 \\
(4068)\end{array}$ & $\begin{array}{r}74.29 \\
(23318)\end{array}$ & $\begin{array}{r}81.6 \\
(4242)\end{array}$ & $\begin{array}{r}79.1 \\
(24827)\end{array}$ & $\begin{array}{r}90.35 \\
(4697)\end{array}$ & $\begin{array}{r}78.88 \\
(24758)\end{array}$ & $\begin{array}{r}93.73 \\
(4873)\end{array}$ & $\begin{array}{r}85.2 \\
(26741)\end{array}$ \\
\hline High-high & $\begin{array}{l}1.06 \\
(55)\end{array}$ & $\begin{array}{r}9.63 \\
(3021)\end{array}$ & $\begin{array}{l}1.25 \\
(65)\end{array}$ & $\begin{array}{r}7.77 \\
(2440)\end{array}$ & $\begin{array}{r}4.69 \\
(244)\end{array}$ & $\begin{array}{r}5.72 \\
(1794)\end{array}$ & $\begin{array}{l}1.85 \\
(96)\end{array}$ & $\begin{array}{r}3.73 \\
(1170)\end{array}$ \\
\hline Low-Low & 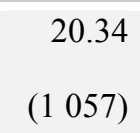 & $\begin{array}{r}11.51 \\
(3614)\end{array}$ & $\begin{array}{l}15.17 \\
(789)\end{array}$ & $\begin{array}{r}9.37 \\
(2942)\end{array}$ & $\begin{array}{r}3.92 \\
(204)\end{array}$ & $\begin{array}{r}9.77 \\
(3067)\end{array}$ & $\begin{array}{r}3.33 \\
(173)\end{array}$ & $\begin{array}{r}5.61 \\
(1762)\end{array}$ \\
\hline High-low & $\begin{array}{r}0.13 \\
(7)\end{array}$ & $\begin{array}{r}2.74 \\
(861)\end{array}$ & $\begin{array}{r}0.15 \\
(8)\end{array}$ & $\begin{array}{r}2.17 \\
(680)\end{array}$ & $\begin{array}{l}0.35 \\
(18)\end{array}$ & $\begin{array}{r}3.44 \\
(1081)\end{array}$ & $\begin{array}{l}0.21 \\
(11)\end{array}$ & $\begin{array}{r}3.78 \\
(1186)\end{array}$ \\
\hline Low-high & $\begin{array}{r}0.12 \\
(6)\end{array}$ & $\begin{array}{r}1.81 \\
(567)\end{array}$ & $\begin{array}{l}1.71 \\
(89)\end{array}$ & $\begin{array}{r}1.57 \\
(492)\end{array}$ & $\begin{array}{l}0.58 \\
(30)\end{array}$ & $\begin{array}{r}2.17 \\
(681)\end{array}$ & $\begin{array}{l}0.77 \\
(40)\end{array}$ & $\begin{array}{r}1.66 \\
(522)\end{array}$ \\
\hline
\end{tabular}

Note: The absolute number of cluster types for each employment form appears in parenthesis 
Figure 13. Bivariate Global Moran's I results, by population characteristic (Significant at $p=0.001$ )

\begin{tabular}{|c|c|c|c|c|}
\hline & PT & CLD & Interim & Subsidized \\
\hline Primary sector & 0.0323 & 0.0459 & 0.0057 & 0.0134 \\
\hline Secondary sector & -0.0633 & -0.083 & 0.0575 & -0.0288 \\
\hline Tertiary sector & -0.0644 & -0.0259 & -0.0183 & -0.0362 \\
\hline Public sector & 0.0825 & 0.0502 & -0.0241 & 0.047 \\
\hline Unemployment & 0.06 & 0.0512 & 0.0349 & 0.0735 \\
\hline Net revenue & -0.065 & -0.0333 & -0.02 & -0.0267 \\
\hline No university & 0.0743 & 0.1 & 0.09 & 0.07 \\
\hline Some university & -0.0155 & -0.0466 & -0.1081 & -0.0502 \\
\hline Female population & -0.0446 & -0.0251 & -0.0083 & -0.0191 \\
\hline
\end{tabular}

